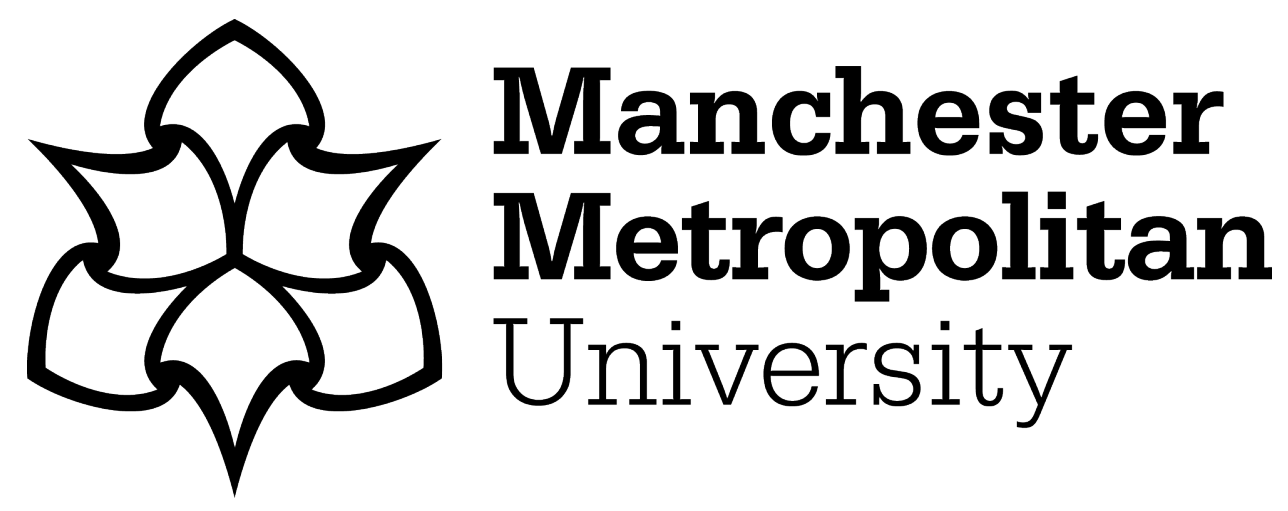

Ryan, Sara ORCID logoORCID: https://orcid.org/0000-0002-7406-1610 (2019) NHS Inquiries and Investigations; an Exemplar in Peculiarity and Assumption. Political Quarterly, 90 (2). pp. 224-228. ISSN 0032-3179

Downloaded from: https://e-space.mmu.ac.uk/627798/

Version: Accepted Version

Publisher: Wiley

DOI: https://doi.org/10.1111/1467-923X.12703

Please cite the published version 


\title{
NHS inquiries and investigations; an exemplar in peculiarity and assumption
}

\section{Sara Ryan}

\begin{abstract}
There is little research focusing on how bereaved families experience NHS inquiries and investigations. Despite this gap, there is a consistent assumption that these processes provide families with catharsis. Drawing on my personal experiences of NHS investigations over a five year period after the death of our son, Connor Sparrowhawk, I suggest the assumption of catharsis is misplaced and works to erase the considerable emotional 'accountability' labour families undertake during these processes. I further question whether inquiries or investigations are an effective way of holding stakeholders to account. I conclude with two points; first, qualitative research is needed to better understand bereaved family experiences of inquiries and investigations and second, the 'lessons learned' objective underpinning inquiries should be replaced with 'leading to demonstrable change' which is what families typically want.
\end{abstract}

\section{Keywords}

inquiries, investigations, NHS, bereavement, accountability

There is little research focusing on bereaved families and NHS inquiries and investigations and, as a consequence, we know very little about their experiences of these processes. This is a considerable gap given that inquiries and investigations can continue for extended periods of time, cost substantial amounts of money and may potentially generate further harm and distress for the families involved. In this paper I explore two of the objectives of inquiries included in Geoffrey Howe's typographyi; 'providing catharsis or therapeutic exposure' and 'holding people or organisations to account'. I suggest that the presumption of catharsis is misplaced and question whether inquiry or investigation processes are an effective way of holding key stakeholders to account or whether they provide an almost exculpatory opportunity for expressions of regret or apology to be seen as sufficient. I draw on my personal experiences of NHS investigation processes across a five year period after the preventable death of our 18 year old son, Connor, also known as Laughing Boy or LB, in an NHS hospital in July 2013. Connor was diagnosed with autism and learning disabilities.

In November 2018, the Health Foundation hosted an event called '50 Years of NHS Public Inquiries' in London. This was attended by several inquiry leaders from past decades and other relevant professionals. I was the only family member present. Reference was made across the day to the catharsis NHS inquiries generate for family members. Given the paucity of evidence in this area, it is not clear what the basis is for this presumption by Howe or later commentators. In 2003, Walshe" stated "The inquiry may offer a cathartic release, and an opportunity for reconciliation and resolution". A decade later Black and Mays iii reflected on the chaotic nature of inquiries in terms of their instigation, process and value, concluding that inquiries are "public exercises in catharsis, a way of purging public anger whilst also highlighting areas of serious concern and policy failure that need remediation".

Catharsis is not something I have heard bereaved families describe either experiencing or seeking from inquiry or investigation processes. Instead, I have repeatedly in person, on social media, at 
patient safety events, conferences and meetings with public sector bodies such as the NHS and the Care Quality Commission (CQC), listened to families state that their aim is quite simply to prevent other families suffering the loss that they have experienced. This is presented as a pragmatic consideration which may be underpinned by strong emotions but without articulation of the importance of experiencing catharsis or therapeutic exposure. Catharsis is not a term I would use to describe my experiences of the investigation processes. I can imagine it may be generated in a large public inquiry with particular characteristics. For example, the Hillsborough inquest involved nearly 100 families with very similar experiences of the catastrophic event at the Sheffield Wednesday stadium, a campaign period of over two decades followed by a two year inquest which many families attended daily. The intensity of this process could enable bonds to be formed between family members and generate a collective experience of catharsis at the end of the inquiry. Again, there is no evidence to substantiate this.

My concern is that the assumption that a cathartic release is a positive (and sought after) outcome of an inquiry or investigation may reduce the process to little more than a nod to harmed families and the wider public leaving unrealised the effective change that is so important to families.

\section{'Catharis' in practice}

Families are not typically familiar with the processes that should happen after the unexpected death or serious harm of a patient and will quite likely assume that the NHS Trust will act appropriately and undertake a full and thorough investigation. There is no equivalent of a police liaison officer in the NHS to guide and support families. In our experience, which is not unusual, the Trust argued that Connor died of natural causes and began a process of obstruction and denial that was to last nearly five years ${ }^{\text {iv }}$. The ease with which this was implemented suggests it was not an unfamiliar process to them.

The investigatory processes around Connor's death eventually involved two independent investigations by an international consultancy called Verita. One focused on what happened in the unit at the time of Connor's death [Verita 1] and a second, wider, investigation focused on the recent takeover by the NHS Trust of the Oxfordshire provision in which Connor died [Verita 2]. We received a copy of Verita 1 in February 2014, seven months after Connor's death. During this time there had been repeated obstructions by the Trust in terms of disclosing documents, organising legal representation for certain bands of staff during investigation interviews, and delaying publication of the report. I can remember reading the report with a sense of horror, distress and deep sadness. Unsurprisingly, the reviewers found that Connor's death was preventable and listed a comprehensive set of failings.

Verita 2 was equally difficult to read albeit for different reasons. The reviewers identified a range of failings in the takeover process of the Oxfordshire provision but concluded that these did not contribute to Connor's death. This review was not completed until October 2015 coinciding with Connor's two week inquest.

The inquest involved a jury and eight separate legal counsels. After some very challenging questioning and exchanges, the jury determined that Connor died as an outcome of serious failings by the Trust. The Coroner issued a Prevention of Future Deaths report to the Trust around their epilepsy protocols. The baton was then passed from the police to the Health and Safety Executive (HSE) to further investigate whether the Trust should face a criminal prosecution. In March 2018 the Trust were charged with the death of Connor and a second patient under Health and Safety Law and pleaded guilty at Oxford Crown Court. The sentencing remarks by Mr Justice 
Stuart-Smith captured the 'time consuming and punishing campaign' we had fought and stated "it is clear on the evidence that Dr Ryan in particular faced not merely resistance but entirely unjustified criticism as she pursued her Justice for LB campaign." The Trust were fined $f 2 m$, the biggest fine in the history of the NHS.

\section{Catharsis}

/kə'Oa:sis/

noun

The process of releasing, and thereby providing relief from, strong or repressed emotions.

The experience of gaining accountability for Connor's death involved several steps across a period of five years including publication the two investigation reports, the inquest and criminal prosecution of the Trust. There is considerable, emotional labour for families behind each of these steps which involves, and is exacerbated by, lengthy delays, numerous meetings (often some way from home), reading lengthy documents, draft reports and legal submissions, and revisiting harrowing detail and medical records. The impact of this labour is substantial and interrupts evenings, weekends and even holidays. The weekend after Connor's inquest, I was invited to appear on the BBC Breakfast news programme and the presenters kept hinting at catharsis; "You must feel pleased/vindicated that..."

"I just feel sad," I replied.

Three years later, the comprehensiveness of the Judge's sentencing remarks at the HSE prosecution generated a sense of finality; that justice had finally been served. It was the right outcome. The size of the fine would make it clear to other Trusts that they needed to improve the standards of care provided to learning disabled and autistic patients. I felt relief that the Trust had been held to account and that an excruciating, exhausting and distressing battle was over. At the same time, Connor was dead and we had learned that the failings that contributed to his death were worse than we imagined. The pressures of these processes took their toll emotionally and physically.

There is little doubt that, for the families involved, inquiries and investigations (or noninvestigations) can compound and prolong experiences of grief ${ }^{v}$. There is variability in practice across NHS Trusts with different models of investigation despite a Serious Incident Framework published by NHS Improvement ${ }^{\mathrm{vi}}$. The distress that poorly conducted investigations could cause families was recognised in the Parliamentary and Health Ombudsman review into the quality of NHS complaints which involved serious or avoidable harm vii. The review concluded that investigation processes were not consistent, reliable or good enough, staff did not feel supported in their investigatory role and there were missed opportunities for learning. A UK study viii of health professionals' perceptions of the NHS 'Being Open' policy found:

"Even when the best of open disclosure practices are followed, patients and relatives may remain hurt, angry and upset and will not always forgive health care professionals or services. They may continue to pursue further explanations even after what staff believe were comprehensive enquiries, may be unwilling to accept proffered apologies and may still wish to pursue legal claims against health care providers."

A review into the preventable deaths of patients in mental health and learning disability services at the Trust in which Connor died highlighted issues around the involvement of families. The 
authors raised the following questions; 'Are we involving families in the right way? How do we know? How can we improve involvement? What is best practice for family involvement? ${ }^{\text {'ix }} A$ report published this month highlighted how Trusts continue to fail to engage with bereaved families because of a lack of training and fear among staff of the potential consequences for them professionally ${ }^{x}$. It seems peculiar that the NHS continues to manage these interactional practices which should be underpinned by honesty, transparency and kindness so consistently poorly.

Walshe earlier linked catharsis with resolution and reconciliation and it was clear at the Health Foundation event that at least one Chair of a public inquiry felt this can happen during the inquiry process as family members come face to face with staff members involved in their relatives' care. Again, there is no research evidence to substantiate this. From my experience, the eventual outcome of the investigations into Connor's death was fair and just. The Trust repeatedly stated that lessons had been learned. Families who do not get this resolution, of which there are several high profile examples, can fight for decades for accountability. The development of social media platforms has created a space for some families to publicly share their accounts of the process, making clear the harm generated by a lack of comprehensive investigation or an unsatisfactory outcome of an investigation. For example, there have been several inquests reported in the public domain in the past year in which coroners have reached unexpected conclusions despite apparently strong evidence that neglect was involved in the death of a patient ${ }^{\mathrm{xi}}$.

Those advocating catharsis are, I suggest, imposing their view of what they think families should feel, or ought to feel at the end of an inquiry or investigation. It is, perhaps, wishful thinking, underpinned by a recognition that preventable harm has occurred. The assumption, however, creates a neat (and arguably, appealing) leap from start to finish, from death or serious harm to justice and accountability effectively erasing the months and years of emotional 'accountability' labour conducted by families at a time when they should be supported in their grief.

\section{An effective mechanism for accountability?}

Various commentators have highlighted the seemingly ad hoc and inconsistent models of NHS inquiries and investigations and questioned how effective they actually are. Nearly two decades ago Walshe made straightforward recommendations to try to inject rigour and consistency into the inquiry process ${ }^{\mathrm{xii}}$. These included learning what works best in terms of different types of inquiries and conducting a comparative review of different models of inquiry. Walshe also highlighted the absence of any understanding of the experience of inquiries both by families and staff staff; "a qualitative study of the use of inquiries would draw on the extensive recent and current experience of major inquiries in the NHS [...] and could help to promote a greater dialogue about the future use of inquiries."

One year on from the HSE prosecution we have heard anecdotally that there is little real change at the NHS Trust involved. The same problems are continuing and, in the wider context of the field of autism and learning disability provision, people are continuing to lead impoverished lives with no change in the mortality rates for these groups of patients. The Prevention of Future Deaths report generated a response from the Trust around 'lessons learned' and disappeared into a pool of similar reports from Coroners across the country. The various investigations and reviews into Connor's death have not lead to much, if any, discernible change. Having reached the end of the investigation journey, we are left unconvinced that what happened to Connor will never happen to another patient.

Walshe (in this edition) offers an epistemological critique of inquiry methods and concludes by 
questioning whether these are effective at addressing the first two objectives in Howe's typology; 'finding the facts' and 'learning from events'. He suggests inquiries may serve other purposes such as providing opportunities for catharsis or holding stakeholders to account. I have argued here that we have no evidence to support the claim for catharsis or emotional release and the idea of holding stakeholders 'to account' is a problematic concept. Saying sorry and, in Connor's case, pleading guilty in a criminal prosecution is one thing but without the actual change that families seek, it is a hollow outcome. Maden ${ }^{\text {xiii }}$ argues it is doubtful that inquiries could 'satisfy' bereaved relatives given the enormity of their loss and refers to an annexe in the Jason Mitchell inquiry report in which his family state they are far from satisfied by the report. I have argued here that adding to this loss (rather than easing it in any cathartic way) is the emotional accountability labour that families undertake during the inquiry and investigation process.

I would like to conclude with two points. First, it is imperative that the now long overdue qualitative research is conducted into how bereaved families experience NHS inquiry and investigation processes. We need to better understand both how these processes are experienced and what families hope to gain from them. Second, the objective of 'lessons learned' should be replaced with a new objective; 'leading to demonstrable change' to provide families with reassurance that changes will be implemented as an outcome of their loved one's death.

\section{Word count: 2832}

\footnotetext{
' Howe G. The management of public inquiries. Political Quarterly 1999; 70(3):294-304.

ii Walshe K. Inquiries: learning from failure in the NHS? London: Nuffield Trust, 2003. https://www.nuffieldtrust.org.uk/files/2017-01/inquiries-learning-from-failure-nhs-web-final.pdf

iii Black, N. and Mays, N., 2013. Public inquiries into health care in the UK: a sound basis for policy-making? Journal of Health Services Research and Policy. 2013:18(3) 129-131.

iv https://www.theguardian.com/society/2018/mar/26/nhs-trust-fined-2m-over-death-of-teenager-connorsparrowhawk Accessed 13.3.19

$\checkmark$ Titcombe, J., Parent-activated medical emergency teams: a parent's perspective. BMJ Quality \& Safety, 2015; 24: 182-183.

vi https://improvement.nhs.uk/resources/serious-incident-framework/ Accessed 11.3.19

vii Parliamentary and health service ombudsman report. 2015. A review into the quality of NHS complaints investigations where serious or avoidable harm has been alleged. https://www.ombuds-

man.org.uk/sites/default/files/A_review_into_the_quality_of_NHS_complaints_investig ations_where_serious_or_avoidable_harm_has_been_alleged.pdf

viii Birks, Y., Entwistle, V., Harrison, R., Bosanquet, K., Watt, I. and ledema, R., 2015. Being open about unanticipated problems in health care: the challenges of uncertainties. Journal of health services research \& policy, 20(1_suppl), pp.54-60. (p59)

ix Mazars 2015 https://www.england.nhs.uk/south/wp-content/uploads/sites/6/2015/12/mazars-rep.pdf

${ }^{x}$ Care Quality Commission. Learning from Deaths. A review of the first year of NHS trusts implementing the national guidance. https://www.cqc.org.uk/sites/default/files/20190315-LfD-Driving-Improvement-reportFINAL.pdf

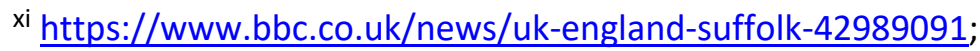
https://www.google.com/search?q=danny+tozer+inquest\&oq=danny+tozer+inquest\&aqs=chrome..69i57i0.3892i0j4\&sourceid=chrome\&ie=UTF-8
}

xiii Maden, A. (1999). Inquiries after homicide. Psychological Medicine, 29(6), 1472-1476. 